\title{
Isolation of antifungal-resistant yeasts from bulk milk in Japan
}

\author{
Ryoka MIYAKE ${ }^{1)}$, Takakaki ITO2), Hiroshi KAMATA ${ }^{3)}$ and Rui KANO ${ }^{1) *}$ \\ 1)Veterinary Dermatology, Nihon University College of Bioresource Sciences, 1866 Kameino, Fusisawa, \\ Kanagawa 252-0880, Japan \\ ${ }^{2)}$ Veterinary Hospital Aichi P.F.A.M.A.A., 91-1 Oike, Hane-cho, Okazaki, Aichi 444-0816, Japan \\ ${ }^{3)}$ Veterinary Pathobiology, Nihon University College of Bioresource Sciences, 1866 Kameino, Fusisawa, \\ Kanagawa 252-0880, Japan
}

J. Vet. Med. Sci.

83(7): 1090-1092, 2021

doi: 10.1292/jvms.21-0023

Received: 12 January 2021

Accepted: 6 May 2021

Advanced Epub:

9 June 2021
ABSTRACT. We isolated ascomycetous yeasts including Candida species, that originally belonged to the genus Candida, from bulk milk in the Aichi area of Japan, and determined the minimum inhibitory concentrations (MICs) of antifungal drugs on these isolates by conducting E-tests. We isolated 7 human pathogenic species (14 isolates) from 14 bulk milk samples: 5 Candida species of yeasts, and 2 Candida-related species. Two isolates of $C$. albicans and C. inconspicua were resistant to fluconazole (MIC $>32 \mathrm{mg} / \mathrm{l})$. One isolate of $C$. krusei was resistant to both azoles (fluconazole: $>256 \mathrm{mg} / \mathrm{ml}$ and itraconazole: $4 \mathrm{mg} / \mathrm{l}$ ). One isolate of $C$. catenulata might be resistant to amphotericin B (>32 mg/l).

KEY WORDS: antifungal resistance, bulk milk, Candida, cow, susceptibility testing

Candidiasis is a common yeast infection that is an opportunistic infection in humans. Candida albicans is the most common and significant species that causes candidiasis, although non-albicans Candida species, such as C. glabrata, C. parapsilosis, C. guilliermondii, and C. krusei (currently reclassified as Pichia kudriavzevii), are also known to be causative agents of human Candida infections $[1,2]$. Importantly, there has been a recent increase in infections due to non-albicans Candida species that exhibit resistance to widely used antifungal agents, such as fluconazole (FLZ) and micafungin, and they are thus associated with a high mortality rate [1,2]. Moreover, the proportion of non-albicans Candida species exhibits geographical differences. C. glabrata is generally more common in Western countries, whereas $C$. parapsilosis is frequently isolated in Latin America. $C$. tropicalis is more common in Asia [7]. Therefore, continual surveillance is required to monitor the emergence of these resistant Candida species in each country $[1,2]$. Candida species are also a part of the normal flora of skin, the mouth, vagina, and gastrointestinal tract in humans and animals. As well as being a pathogen of bovine chronic mastitis, it can be extracted from chronic mastitis milk [5].

In this study, we isolated Candida species, including pathogenic yeasts that originally belonged to the genus Candida, from bulk milk in the Aichi area of Japan, and determined the minimum inhibitory concentrations (MICs) of antifungal drugs on these isolates by conducting E-tests.

A total of 24 bulk milk samples were collected for regular bulk milk tests in 2019; all were Holstein cow milk collected at 24 dairy farms located in the Aichi region of Japan. Each milk sample was inoculated directly onto a CHROMagar ${ }^{\mathrm{TM}}$ Candida (Kanto Chemical Co., Inc., Tokyo, Japan) and incubated at $32^{\circ} \mathrm{C}$ for 2 days. Fungal colonies were then identified as Candida species based on the sequence homology of the internal transcribed spacer (ITS) region (ITS1-5.8S-ITS2) of ribosomal DNA as described previously [6]. The universal fungal primers ITS-5 (5'-GGAAGTAAAAGTCGTAACAAGG-3') and ITS-4 (5'-TCCTCCGCTTATTGATATGC-3') were used to amplify the ITS region of the isolates [6]. The molecular identification of fungal species was carried out according to a previous report [8].

E-tests were performed to determine the MICs of amphotericin B (AMB), FLZ, itraconazole (ITZ), and voriconazole (VRZ) for the 14 isolates of Candida species collected from 14 bulk milk samples according to the E-test Technical Guide 10 (bioMérieux Japan, Tokyo, Japan). Candida species were classified as being resistant to FLZ, ITZ, and VRZ according to the clinical breakpoints outlined in the M27-A3 guidelines prepared by the Clinical Laboratory Standards Institute [4]. The MICs of FLZ, ITZ, and VRZ in the resistant strains were determined to be $>64 \mathrm{mg} / \mathrm{l},>1 \mathrm{mg} / \mathrm{l}$, and $>4 \mathrm{mg} / \mathrm{l}$, respectively [3].

We isolated 7 human pathogenic species among the 14 isolates from the 14 bulk milk samples; the human pathogenic species comprised 5 Candida species of yeast (C. albicans, C. catenulate, C. inconspicua, C. parapsilosis, and C. tropicalis) and 2 Candida-related species (Pichia kudriavzevii and Wickerhamiella pararugosa; Table 1).

The MICs for all 14 isolates were $<0.002$ to $>32 \mathrm{mg} / 1$ for AMB, 0.064 to $>256 \mathrm{mg} / \mathrm{l}$ for FLZ, 0.004 to $4 \mathrm{mg} / 1$ for ITZ, and 
Table 1. Minimum inhibitory concentrations (mg/l) of antifungal drugs against the tested dermatophyte species

\begin{tabular}{|c|c|c|c|c|c|c|c|}
\hline Strain number & $\begin{array}{c}\text { Balk milk } \\
\text { number }\end{array}$ & Isolated yeast species & Former name & Amphotericin B & Fluconazole & Itraconazole & Voriconazole \\
\hline No.4 & $35 \mathrm{P}$ & Wickerhamiella pararugosa & C. pararugos & 0.064 & 1.000 & 0.064 & 0.006 \\
\hline No.5 & $59 \mathrm{P}$ & Candida albicans & & 0.008 & 1.000 & 0.023 & 0.004 \\
\hline No.6 & $65 \mathrm{P}$ & W. pararugosa & C. pararugos & 0.250 & 2.000 & 0.094 & $<0.002$ \\
\hline No.7 & $66 \mathrm{P}$ & C. parapsilosis & & $<0.002$ & 0.125 & 0.004 & 0.004 \\
\hline No.14 & $194 \mathrm{P}$ & Pichia kudriavzevii & C. krusei & 1.500 & $>256.0$ & 4.000 & 0.250 \\
\hline No.15 & $194 \mathrm{~W}$ & C. albicans & & 0.380 & $>256.0$ & 0.250 & $<0.002$ \\
\hline No.16 & $198 \mathrm{~W}$ & C. inconspicua & & 0.230 & $>256.0$ & 0.125 & $<0.002$ \\
\hline No.17 & $207 \mathrm{P}$ & C. parapsilosis & & 0.380 & 0.064 & 0.094 & 0.004 \\
\hline No.18 & $231 \mathrm{P}$ & W. pararugosa & C. pararugos & 0.016 & 3.000 & 0.064 & 0.320 \\
\hline No.19 & $245 \mathrm{P}$ & C. parapsilosis & & 0.064 & 0.125 & 0.064 & 0.006 \\
\hline No.20 & 247B & C. catenulata & & $>32.00$ & 2.000 & 0.064 & $<0.002$ \\
\hline No.21 & $247 \mathrm{G}$ & C. tropicalis & & 0.500 & 0.250 & 0.064 & $<0.002$ \\
\hline No.22 & $263 \mathrm{P}$ & C. parapsilosis & & 0.016 & 0.094 & 0.064 & $<0.002$ \\
\hline No.23 & $268 \mathrm{P}$ & W. pararugosa & C. pararugos & 0.380 & 1.500 & 0.250 & $<0.002$ \\
\hline
\end{tabular}

$<0.002$ to $0.32 \mathrm{mg} / \mathrm{l}$ for VRZ (Table 1). Two isolates of C. albicans and C. inconspicua (Nos. 15 and 16) were resistant to FLZ (MIC $>32 \mathrm{mg} / \mathrm{l}$; Table 1). One isolate of P. kudriavzevii (No. 14) was resistant to both azoles (FLZ: $>256 \mathrm{mg} / \mathrm{ml} \mathrm{and} \mathrm{ITZ:} 4 \mathrm{mg} / \mathrm{l}$; Table 1). One isolate of $C$. catenulata (No. 20) might be resistant to AMB (MIC $>32 \mathrm{mg} / \mathrm{l}$; Table 1).

To our knowledge, this is the first report of antifungal-resistant human pathogenic yeast isolates from bulk milk. In particular, C. albicans, C. parapsilosis, C. tropicalis P. kudriavzevii are intrinsically resistant or less susceptible to antifungals [1,2], and they have also been isolated from bovine clinical mastitis cases in Japan [5]. Based on our findings, we suspect that the prevalence of antifungal-resistant pathogenic yeasts is detected in bulk milk in Japan. Of course, in Japan, raw milk is pasteurized before it is shipped, so it is unlikely for consumers to become infected by antifungal-resistant yeasts in milk. However, if drug-resistant pathogenic yeast is present in the dairy cow's udder, there is concern that beef contaminated with the yeasts may be shipped to markets.

It has been reported that the increasing use of azole fungicides in agriculture has induced azole resistance in Aspergillus species in the environment. The European Centre for Disease Prevention and Control issued a risk assessment report on azole resistance in Aspergillus species and its possible link to the environmental usage of azole fungicides (http://www.life-worldwide.org/ media-centre/article/ecdc-issues-risk-assessment-on-azole-resistance-in-aspergillus-from-environ/). An increase in azole antifungalresistant Aspergillus strains that cause serious human infections has been detected in several European countries. In addition, residual azole fungicides remaining in cattle feed may also have induced resistance. Sidrim et al. [9] reported that humans, domesticated animals, wild animals, and aquatic and/or terrestrial environments are likely to carry resistant microorganisms, and can spread them to other animals and natural environments. Therefore, azole-resistant Candida species may spread between cattle in the same environment.

CONFLICT OF INTEREST. The authors declare no conflict of interest.

\section{REFERENCES}

1. Arastehfar, A., Lass-Flörl, C., Garcia-Rubio, R., Daneshnia, F., Ilkit, M., Boekhout, T., Gabaldon, T. and Perlin, D. S. 2020. The quiet and underappreciated rise of drug-resistant invasive fungal pathogens. J. Fungi (Basel) 6: 138. [Medline] [CrossRef]

2. Arendrup, M. C. and Patterson, T. F. 2017. Multidrug-resistant Candida: epidemiology, molecular mechanisms, and treatment. J. Infect. Dis. 216 (suppl_3): S445-S451.

3. Cantón, E., Espinel-Ingroff, A. and Pemán, J. 2009. Trends in antifungal susceptibility testing using CLSI reference and commercial methods. Expert Rev. Anti Infect. Ther. 7: 107-119. [Medline] [CrossRef]

4. CLSI. 2008. Reference Method for Broth Dilution Antifungal Susceptibility Testing of Yeasts; approved standard third edition. CLSI document M27-A3. Clinical Laboratory Standards Institute, Wayne, Philadelphia.

5. Hayashi, T., Sugita, T., Hata, E., Katsuda, K., Zhang, E., Kiku, Y., Sugawara, K., Ozawa, T., Matsubara, T., Ando, T., Obayashi, T., Ito, T., Yabusaki, T., Kudo, K., Yamamoto, H., Koiwa, M., Oshida, T., Tagawa, Y. and Kawai, K. 2013. Molecular-based identification of yeasts isolated from bovine clinical mastitis in Japan. J. Vet. Med. Sci. 75: 387-390. [Medline] [CrossRef]

6. Hinrikson, H. P., Hurst, S. F., Lott, T. J., Warnock, D. W. and Morrison, C. J. 2005. Assessment of ribosomal large-subunit D1-D2, internal transcribed spacer 1, and internal transcribed spacer 2 regions as targets for molecular identification of medically important Aspergillus species. J. Clin. Microbiol. 43: 2092-2103. [Medline] [CrossRef]

7. Hirano, R., Sakamoto, Y., Kitazawa, J., Yamamoto, S. and Kayaba, H. 2018. Epidemiology, practice patterns, and prognostic factors for candidemia; and characteristics of fourteen patients with breakthrough Candida bloodstream infections: a single tertiary hospital experience in Japan. Infect. Drug Resist. 11: 821-833. [Medline] [CrossRef] 
8. Kano, R., Sakai, M., Hiyama, M. and Tani, K. 2019. Isolation of Aspergillus caninus (synonym: Phialosimplex caninus) from a canine iliac lymph node. Mycopathologia 184: 335-339. [Medline] [CrossRef]

9. Sidrim, J. J. C., Carvalho, V. L., de Souza Collares Maia Castelo-Branco, D., Brilhante, R. S. N., de Melo Guedes, G. M., Barbosa, G. R., Lazzarini, S. M., Oliveira, D. C. R., de Meirelles, A. C. O., Attademo, F. L. N., da Bôaviagem Freire, A. C., de Aquino Pereira-Neto, W., de Aguiar Cordeiro, R., Moreira, J. L. B. and Rocha, M. F. G. 2016. Antifungal resistance and virulence among Candida spp. from captive Amazonian manatees and west Indian manatees: potential impacts on animal and environmental health. EcoHealth 13: 328-338. [Medline] [CrossRef] 